\title{
LOCKED NAILING OF COMMINUTED AND UNSTABLE FRACTURES OF THE FEMUR
}

\author{
JENS OLE SØJBJERG， SøREN EISKJAER，FLEMMING MØLLER-LARSEN
}

From the University of Aarhus, Denmark

\begin{abstract}
Forty comminuted or unstable fractures of the femoral shaft were treated by closed intramedullary reaming and locked nailing. Twenty-four fractures were severely comminuted, and the other 16, in the distal or proximal third of the shaft, were classified as unstable.

At 12 to 30 months postoperatively all the fractures had healed. Three patients had lateral rotation deformity of $5^{\circ}$ to $10^{\circ}$, three had shortening of 1 to $2 \mathrm{~cm}$ and two had lengthening of about $1 \mathrm{~cm}$. There were no infections or delayed unions. Closed intramedullary locked nailing can provide stability in fractures of the femoral shaft, irrespective of the degree of comminution and the site of injury.
\end{abstract}

The treatment of comminuted fractures of the femoral shaft has been changed by the introduction of the locked intramedullary nail. Conservative treatment yields acceptable results but requires a long hospital stay and may yield a high percentage of malunion (Montgomery and Mooney 1981; Johnson, Johnson and Parker 1984). Operative treatment with rigid plating has a high risk of infection and neither eliminates malunion nor allows early weight-bearing (Magerl et al 1979; Rüedi and Lüscher 1979). Conventional closed intramedullary nailing does not provide rotational or axial stability of comminuted fractures due to the flexibility of the device and lack of fit in the fracture (Winquist and Hansen 1980; Johnson et al 1984; Møller-Larsen, Søjbjerg and Andreassen 1988).

Klemm and Schellmann (1972) and Kempf, Grosse and Beck (1985) introduced the locked intramedullary nail for the treatment of comminuted fractures of the femur. They reported that this method gave axial, rotational and bending stability to the fracture; both series reported low incidences of infection, non-union and malunion.

We report a prospective series of 40 consecutive comminuted or unstable fractures of the femur treated with closed reaming and a locked intramedullary GrosseKempf nail.

J. O. Sejbjerg, MD, Senior Orthopaedic Registrar

S. Eiskjaer, MD, Orthopaedic Registrar

F. Møller-Larsen, MD, Senior Orthopaedic Registrar

Department of Orthopaedic Surgery, Aarhus Kommunehospital, University of Aarhus, DK-8000 Aarhus C, Denmark.

Correspondence should be sent to $\mathrm{Dr} J$. O. Søjbjerg at Orthopaedic Hospital, Randersvej 1, DK-8200 Aarhus N, Denmark.

(C) 1989 British Editorial Society of Bone and Joint Surgery 0301-620X/90/1199\$2.00

J Bone Joint Surg [Br] 1990; 72-B: 23-5.

\section{PATIENTS AND METHODS}

A total of 37 consecutive patients with $\mathbf{4 0}$ comminuted or unstable fractures of the femoral shaft were operated on in 1986 and early 1987.

There were 13 women and 24 men, median age 31 years (range 15 to 83). The fractures were classified for degree of comminution (Winquist and Hansen 1980): 16 were grade 1 or 2 but located in the proximal or distal thirds of the diaphysis and considered unstable, 24 were grade 3 or 4 , mostly in the middle and distal thirds. Eleven fractures were open grade 1 or 2, none were open grade 3 . Thirty-two fractures ( 23 closed and 9 open) were operated on within the first 24 hours. The operative delay in eight fractures was due to other multiple injuries, which required primary treatment. Antibiotic prophylaxis was used routinely.

All fractures were operated on with the patient in a supine position on a fracture table. After closed reduction, a guide-wire was introduced into the medullary canal from the tip of the greater trochanter, the point of insertion being carefully checked with a image intensifier. Flexible intramedullary reamers were used to increase the diameter of the canal by $0.5 \mathrm{~mm}$ in a stepwise manner to $1 \mathrm{~mm}$ more than the diameter of the nail. The nail diameter was $12 \mathrm{~mm}$ except in five elderly patients with wider medullary canals.

With the nail in place a special jig was used to introduce the proximal diagonal self-tapping bolt. The distal bolts were placed percutaneously with the aid of the image intensifier using the free hand technique described by Thoresen et al (1985). The patients were mobilised on crutches after removal of the drain, and full weight-bearing was allowed when callus was visible on the radiograph.

All patients were reviewed clinically and radiograph- 
ically until fully healed. Final follow-up was at 12 to 30 months postoperatively (median 17 months) except for one patient who died after six months from an unrelated disease, by which time the femoral fracture had healed.

\section{RESULTS}

The 16 patients with an isolated fracture were discharged from hospital on average 11 days (range 5 to 25 ) after operation; full weight-bearing was allowed at a median of 4.5 weeks (range 2 to 6). The median time to union defined by the presence of adequate radiographic callus was 12 weeks (range 10 to 22). One patient aged 77 years remained in hospital for three months for domestic reasons.

The 20 patients with multiple injuries had a mean stay in the trauma unit of 38 days (range 14 to 80 ); weight-bearing was allowed as soon as the patients could tolerate it. In none of these patients did the femoral fracture cause delay in starting rehabilitation.

The complications in our series are shown in Table I. There were no cases of non-union or infection, and no patient complained of any significant pain. The five grade 4 fractures had healed with some minor lengthening or shortening and six fractures had malunion with lateral rotation, valgus deformity or anteroposterior angulation of between $5^{\circ}$ and $10^{\circ}$. None of these patients had serious complaints in relation to the malunion.

All except one of the patients with no ipsilateral knee injury regained excellent movement of the knee. Two patients had only $60^{\circ}$ of flexion at three months, but after manipulation and physiotherapy both regained flexion to over $120^{\circ}$.

All the fractures had been locked both distally and proximally. Two distal bolts backed out after two and three months respectively and had to be removed. In three patients the distal bolts caused localised pain from a bursa; these bolts were removed. The problems with distal bolts did not interfere with the fracture healing. There was no failures of proximal bolts.

\section{DISCUSSION}

The benefits of closed intramedullary nailing as against conservative treatment or open reduction and rigid internal fixation have been well documented (Rokkanen, Slätis and Vankka 1969; Magerl et al 1979; Rüedi and Lüscher 1979; Winquist and Hansen 1980; Montgomery and Mooney 1981; Johnson et al 1984). The main problems in treating comminuted and unstable femoral shaft fractures are the preservation of length, alignment and rotation. Klemm and Schellmann (1972) and Kempf et al (1985) introduced the locking technique, using bolts both distal and proximal to the fracture to extend the indications for medullary nailing.

In our series, 24 of the fractures were grade 3 or 4 comminuted and the others were unstable and in the
Table I. Complications in $\mathbf{4 0}$ comminuted and unstable fractures of the femur treated by intramedullary locked nailing

\begin{tabular}{lll}
\hline & Number & Range \\
\hline Non-union & 0 & \\
Infection & 0 & \\
Lengthening & 2 & $1 \mathrm{~cm}$ \\
Shortening & 3 & $1 \mathrm{~cm}$ to $2 \mathrm{~cm}$ \\
Knee movement & 3 & $60^{\circ}$ to $90^{\circ}$ \\
Distal bolt & 6 & 1 failure, \\
& & 5 removed \\
Malunion: & & \\
$\quad$ Valgus angulation & 2 & $5^{\circ}$ to $10^{\circ}$ \\
\multicolumn{1}{c}{ Lateral rotation } & 3 & $5^{\circ}$ to $10^{\circ}$ \\
$\quad$ AP angulation & 1 & $9^{\circ}$ \\
$\quad$ Medial rotation & 0 & \\
\hline
\end{tabular}

proximal or distal thirds of the shaft. None of them could have been treated with sufficient rotational stability by conventional nailing. Axial and bending stability could have been obtained in the less comminuted fractures but probably not in the grade 3 and $\mathbf{4}$ fractures, especially if early mobilisation and weight-bearing are goals of treatment.

In our series, five fractures healed with lengthening or shortening of between 1 and $2 \mathrm{~cm}$. Lengthening of the femur is a unique complication to locked medullary nailing, caused by over-correction at the time of operation. Shortening was due to failure to estimate nail length and not to failure of the nail. Such length discrepancy can be avoided by careful determination of the length of the opposite intact femur, and in bilateral fractures by the use of equal length nails. We found that observation of skin tension, the position of the patella and image intensifier checks were the best methods of checking correct rotation and angulation. Our six cases with minor malunion were all due to fixation in these positions; the alignment did not subsequently change.

In our series all fractures were treated with static nailing, that is, both distal and proximal locking; no bolts were removed in an attempt to dynamise the fracture. Thoresen et al (1985) reporting 48 femoral shaft fractures (most treated with dynamic nailing), had the same incidence of malunion as we did, but theirs were generally more severe. This supports the view that dynamic nailing cannot provide sufficient stability to a comminuted fracture. We had no non-union or delayed union in our series, despite lack of the dynamisation recommended by Kempf et al (1985); we feel that this can be omitted.

The lack of infection in our series supports the view that open medullary reaming or plating increases the risk of infection (Magerl et al 1979; Rüedi and Lüscher 1979; 

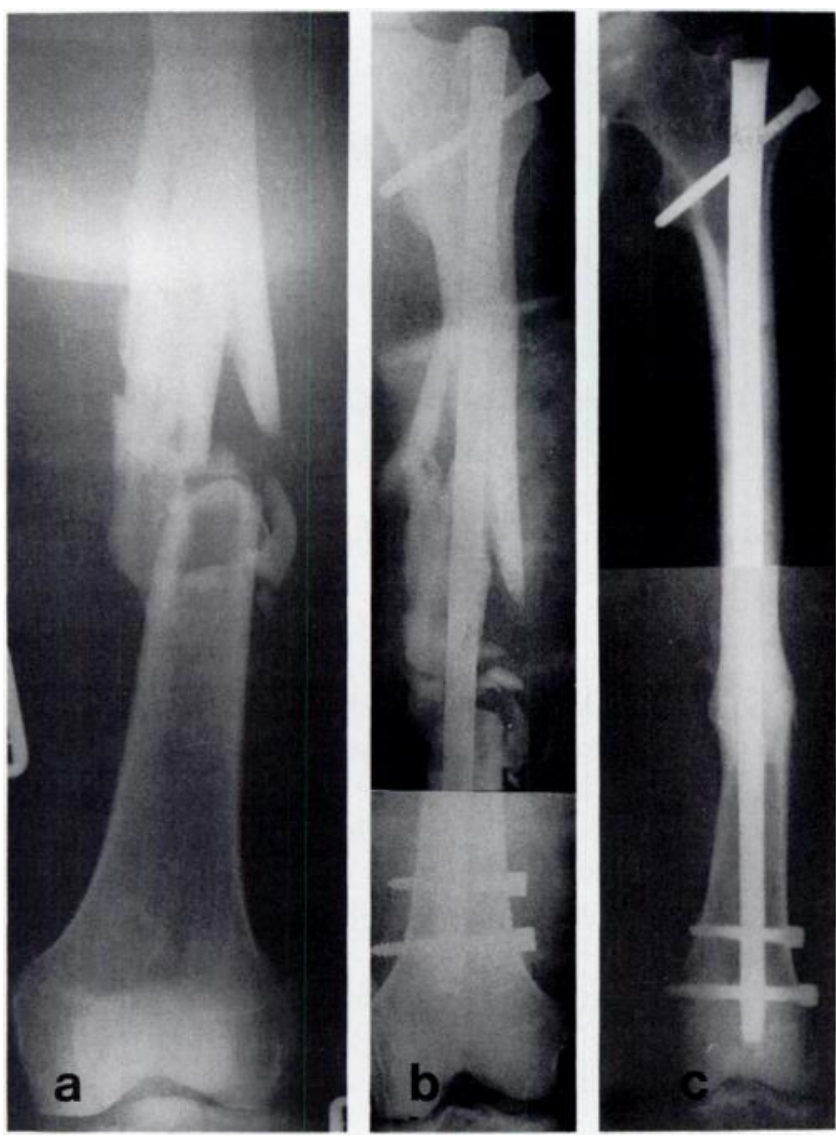

Fig. 1

Grade 4 comminuted fracture of the left femur (a), treated by closed reduction and locked intramedullary nailing (b). At 22 months the fracture has healed (c) and the functional result is excellent.

Johnson et al 1984). We did not intend to achieve an anatomical reduction, but only correct alignment. All our fractures healed and incorporated the displaced fragments in the callus (Fig. 1).

Reaming of the medullary canal destroys the medullary blood supply and weakens the cortex (Kessler et al 1986), but despite this, non-union and refracture are rare after reaming and closed nailing (Winquist, Hansen and Clawson 1984; Kempf et al 1985; Thoresen et al 1985; Johnson, Tencer and Sherman 1987). We tried to minimise reaming, using a $12 \mathrm{~mm}$ nail in most cases. Despite this we had no nail failures. Møller-Larsen et al (1988) found only a slight gain in rigidity after increasing the nail diameter to $14 \mathrm{~mm}$.

Locking of the intramedullary nail requires that the nail itself is more rigid than the original cloverleaf flexible nails. Therefore a proper entry point for the nail is important to avoid complications such as jamming. Christie and Court-Brown (1988) reported four cases of femoral neck fractures due to the use of a lateral starting point, and Johnson et al (1987) stress the importance of posterior placement of the start to reduce the stress on the anterior cortex. We also have found it important to select the appropriate entry point: we used an image intensifier that allowed biplane visualisation of the trochanteric region during the insertion of the guidewire, and had no proximal complications. However, if a lateral or anterior portal is used, then we recommend more extensive reaming, rather than forceful insertion of the nail.

The main drawback of locked medullary nailing is the experience required to perform the procedure (Browner 1986). There are many pitfalls and in our opinion the method should be reserved for surgeons who are experienced with medullary nailing. In our series most cases were operated on by the two senior surgeons. Conclusions. We recommend closed locked medullary nailing for the treatment of all comminuted fractures of the femoral shaft, and feel that dynamisation of the fracture six weeks postoperatively is unnecessary. Reduction and reaming should be a closed procedure, and it seems that reaming should be minimised.

No benefits in any form have been received or will be received from a commercial party related directly or indirectly to the subject of this article.

\section{REFERENCES}

Browner BD. Pitfalls, errors, and complications in the use of locking Küntscher nails. Clin Orthop 1986;212:192-208.

Christie J, Court-Brown C. Femoral neck fracture during closed medullary nailing: brief report. J Bone Joint Surg [Br] 1988: 70B : 670 .

Johnson KD, Johnson DWC, Parker B. Comminuted femoral-shaft fractures: treatment by roller traction, cerclage wires and an intramedullary nail, or an interlocking intramedullary nail. $J$ Bone Joint Surg [Am] 1984; 66-A :1222-35.

Johnson KD, Tencer AF, Sherman MC. Biomechanical factors affecting fracture stability and femoral bursting in closed intramedullary nailing of femoral shaft fractures, with illustrative case presentations. J Orthop Trauma 1987: 1:1-11.

Kempf I, Grosse A, Beck G. Closed locked intramedullary nailing: its application to comminuted fractures of the femur. J Bone Joint Surg $[\mathrm{Am}] 1985 ; 67-\mathrm{A}: 709-20$.

Klemm K, Schellmann WD. Dynamische und statische Verriegelung des Marknagels. Monatsschr Unfallheilkd 1972: $75: 568-75$.

Kessler SB, Hallfeldt KKJ, Perren SM, Schweiberer L. The effects of reaming and intramedullary nailing on fracture healing. Clin Orthop 1986; 212:18-25.

Magerl F, Wyss A, Brunner Ch, Binder W. Plate osteosynthesis of femoral shaft fractures in adults: a follow-up study. Clin Orthop $1979 ; 138: 62-73$.

Montgomery SP, Mooney V. Femur fractures: treatment with roller traction and early ambulation. Clin Orthop 1981: $156: 196-200$

Møller-Larsen F, Sejbjerg JO, Andreassen TT. Torsional stability of interlocking intramedullary nails in experimental femoral shaft fractures. Proceedings of Scandinavian Orthopaedic Association 1988. Acta Orthop Scand 1988; Suppl 227:Vol:59:21

Rokkanen P, Slätis P, Vankka E. Closed or open intramedullary nailing of femoral shaft fractures: a comparison with conservatively treated cases. J Bone Joint Surg [Br] 1969: 51-B:313-23.

Rüedi ThP, Lüscher JN. Results after internal fixation of comminuted fractures of the femoral shaft with DC plates. Clin Orthop 1979: 138:74-6.

Thoresen BO, Alho A, Ekeland A, Stremsee K, Follerás G, Haukebe A. Interlocking intramedullary nailing in femoral shaft fractures: a report of forty-eight cases. J Bone Joint Surg [Am] 1985: 67A: $1313-20$.

Winquist RA, Hansen ST Jr. Comminuted fractures of the femoral shaft treated by intramedullary nailing. Orthop Clin North Am 1980: $11: 633-48$

Winquist RA, Hansen ST Jr, Clawson DK. Closed intramedullary nailing of femoral fractures: a report of five hundred and twenty cases. J Bone Joint Surg [ Am] 1984; 66-A :529-39. 